\title{
Os Juizados Especiais Cíveis de Defesa do Consumidor: a ampliação dos direitos no Estado democrático
}

\author{
Saskya Miranda Lopes * \\ Ruthy Nadia Laniado **
}

\section{Resumo}

O presente trabalho é um estudo de caso que analisa a institucionalização do direito do consumidor com a implantação dos Juizados de Defesa do Consumidor em Salvador, Bahia, no período de 2000 a 2005. Observa como se efetiva o acesso à justiça em atendimento aos princípios e preceitos constitucionais da Carta de 1988. O trabalho estuda tanto o desempenho dos órgãos em tela (o Primeiro e o Segundo Juizados Especiais Cíveis de Defesa do Consumidor) como a visão dos juízes sobre o desempenho dos juizados em relação à sua função constitucional. Este estudo de sociologia política se situa no âmbito da justiça social e da ampliação dos direitos modernos que o Estado operacionaliza por meio de organismos específicos. Os dados revelam que os direitos do consumidor contemplados pelos serviços de justiça prestados pelos Juizados Especiais contribuem para a ampliação e conscientização dos indivíduos vis-à-vis o papel dos direitos nas relações sociais, onde se confrontam os consumidores e as forças econômicas (as empresas) da produção capitalista contemporânea. Por um lado, recorrer aos juizados é importante para confirmar os reclamos do consumidor e educar para entender a relevância dos direitos; por outro, o atendimento dos juizados revela que a ação do Estado em prover esse serviço de justiça nem sempre consegue atender satisfatoriamente à demanda do cidadão devido à falta de recursos para o funcionamento do órgão. No entanto, no geral, é possível dizer que o acesso aos mecanismos públicos de justiça contribui, em médio prazo, para a ampliação da cidadania e para uma cultura política que enfatiza o papel dos direitos nas formas plurais de constituição do sujeito-cidadão hoje.

Palavras-chave: juizados especiais, direito do consumidor, cidadania, democracia.

* Professora Assistente da Universidade Estadual do Piauí. Advogada. Endereço eletrônico: saskya@uol.com.br.

*** Professora Associada do Departamento de Sociologia da Universidade Federal da Bahia. Pesquisadora do CNPQ. Endereço eletrônico: ruthy@ufba.br. 


\section{Introdução}

O s direitos do consumidor representam uma inovação e um avanço na relação entre Estado e cidadão e na ação desse último na esfera pública por meio das demandas que encaminha aos Juizados Especiais Cíveis do Consumidor no Brasil. A relevância desse tema está em reconhecer como interesses individuais da vida cotidiana e lutas políticas de diversas ordens caminham pari passu na participação mais ativa do cidadão para a democratização da sociedade, inclusive no que diz respeito às relações entre indivíduo e mercado em tempos de globalização. A Constituição de 1988 veio a consagrar a multiplicação dos espaços de participação e a transformação de valores de cultura política na vivência das relações de consumo dos indivíduos e no apoio do Estado ao cidadão (direitos consumeristas tutelados).

$\mathrm{O}$ direito do consumidor tem um caráter multifacetado, objeto de debates jurídicos e políticos, pois ele se move na fronteira entre o direito individual e o coletivo, conforme o tipo de queixa do cidadão. Seu aspecto mais contundente para a inovação política e da cidadania é expressar um direito que atende a necessidades individuais, mas que também afetam coletivamente os indivíduosclientes que estão na mesma condição de subordinação às condições do mercado econômico ou de serviços.

A Bahia foi precursora em criar uma instância da justiça para a defesa das pequenas causas e do consumidor em 1985 e tomou a dianteira para a implementação dos Juizados Especiais Cíveis de Defesa do Consumidor entre os estados brasileiros, em 1992. Desde então, após mudanças legais e organizacionais, os juizados específicos para a defesa do consumidor tomaram corpo e se institucionalizaram no Estado. São eles, o Primeiro Juizado Especial Cível de Defesa do Consumidor (do bairro dos Barris) e o Segundo Juizado Especial Cível de Defesa do Consumidor (do bairro de Brotas), que formam o recorte empírico deste trabalho.

A pesquisa realizada em 2006 e 2007 para apoiar este estudo de caso objetivou conhecer a visão dos juízes que lidam com o direito do consumidor a partir do microssistema dos juizados especiais do Estado; também investigou o próprio desempenho 
desses juizados no atendimento das demandas dos consumidores no período 2000-2005. Isto é, estudou o olhar daqueles que atuam na implementação das normas constitucionais que determinam a garantia desse direito inovador para o cidadão, ao diagnosticar as demandas e os processos iniciados no âmbito dos juizados. Os dados informam também a visão dos juízes sobre as condições reais desse tipo de assistência jurídica, ao considerar questões de eficiência, efetividade, reconhecimento dos direitos, produção de novos direitos e valores de cultura política que resultam dessa relação entre Estado e cidadão.

\section{O surgimento dos Juizados Especiais}

É na história do sistema jurídico e democrático norte-americano que se pode traçar a evolução histórica de espaços jurídicos que vieram a promover direitos confluentes com os do consumidor já em décadas mais recentes. A ideia de criar cortes com jurisdição especial e limitada (limited jurisdiction) às pequenas causas foi muito bem aceita e adotada em muitas cidades durante o período de 1913 até 1934, mas foi em 1913, nos Estados Unidos da América, que surgiu o primeiro órgão jurisdicional com atribuição especial para cuidar das pequenas causas, conhecido como poor man's court (FRIEDMAN, 1984).

Por um lado, o crescimento das cidades diversificava e aumentava a mão-de-obra, alargando o número de assalariados no mundo de consumo; por outro lado, o crescimento econômico aumentava as desigualdades de renda e tornava as pessoas vulneráveis ao desemprego e à marginalização social, uma vez que grande parte da população não participava de uma efetiva distribuição de renda. A modificação na estrutura social americana levou à necessidade de criar órgãos especializados em resolver litígios nas novas comunidades urbanas. Tais litígios dificilmente envolviam grandes somas em dinheiro, tendo em vista o perfil econômico da população. Ao mesmo tempo, era preciso dar acesso à justiça para quem não podia custear um processo judicial comum, seja por insuficiência de renda, porque os valores envolvidos eram inferiores às próprias custas processuais, seja para impedir que se fizesse justiça com as 
próprias mãos (MIRANDA, PETRILLO \& OLIVEIRA FILHO, 2004). Após a quebra da bolsa de Nova York em 1929, parece que o objetivo da implantação desses tribunais nos EUA, diante de um contexto de empobrecimento, visava, também, manter a ordem social. De fato, as cortes populares atendem às camadas baixas e médias da população e têm baixo custo para os usuários; tendem a ser informais, dispensando advogados e formalidades processuais que costumam transformar um processo em um ritual misterioso e temeroso aos olhos dos leigos.

Em decorrência de a tradição americana atribuir os julgamentos a um corpo de jurados, algumas dessas cortes admitem a formação de um júri popular caso a parte assim requeira. Atualmente, a nomenclatura original de poor man's court foi substituída, em grande parte das cidades, para small claims courts (corte das pequenas causas ou reclamações), ou ainda common man's court (corte do homem comum). Outras cortes possuem competência limitada (limited jurisdiction), compondo o grupo de tribunais inferiores denominados lower courts. Outras cortes são ainda mais especializadas; podem-se citar, por exemplo, as denominadas justice courts, traffic courts (brigas de trânsito), police courts, municipal courts, mayors courts, juvenile courts (corte da juventude, infância e adolescência) (FRIEDMAN, 1984).

Nos anos sessenta, houve denúncias de que esses juizados especiais eram um exemplo de que essa justiça era manipulada contra os pobres. Os juizados foram acusados de se tornarem postos de cobrança para os empresários, pois eram "cortes dos homens pobres" somente porque os pobres eram levados a elas numa atmosfera intimidativa e forçados a confrontar os poderosos credores ou mesmo o governo. Esse tipo de denúncia levou os Juizados de Pequenas Causas americanos a uma série de reformas. No Juizado Especial de Nova Iorque, por exemplo, não se admite que empresas de cobranças e seguradoras sejam autoras de ações. Em muitas cidades, um serventuário é disponibilizado para ajudar o cidadão a preencher os formulários de ingresso com a ação judicial e, em alguns locais, é oferecida consultoria jurídica gratuita para os usuários.

Para Capelletti (1998), a justiça em geral é de difícil acesso devido aos seguintes pontos: a) custas judiciais: o custo para o 
Estado do aparato judiciário, as custas do processo, os honorários advocatícios, a proporcionalidade dos custos do processo em relação a uma causa de pequeno valor; os efeitos do tempo de duração do processo; b) habilidade de entendimento do direito: a hipossuficiência financeira, técnica ou fática das partes é capaz de desestruturar o equilíbrio do processo - diferentes níveis de conhecimento do direito e do funcionamento da justiça; c) os problemas inerentes aos interesses difusos.

As soluções encontradas, mutatis mutandis, em países da Europa e nos Estados Unidos, para tal situação passaram por três etapas, segundo Capelletti (1998). A primeira diz respeito à disponibilização de uma assistência judiciária constante e gratuita para os pobres, reconhecida como um direito de todo cidadão; tal assistência é levada a efeito através de advogados pagos pelo Estado (ou particulares, ou advogados servidores públicos). A segunda concerne à legitimação da representação de interesses difusos na processualística moderna e sua legitimação ativa para postulação em juízo, tais como os interesses que versam sobre matéria ambiental e de consumo. A busca da representação adequada dos interesses coletivos se fez imperiosa, surgindo até mesmo por meio de instituições como o ombudsman do consumidor, na Suécia, na Noruega e na Dinamarca. Na terceira etapa, surge um novo enfoque para lidar com o litígio, verificando-se uma reforma dos procedimentos judiciais em geral: (a) métodos alternativos para decisão de causas, tais como o juízo arbitral e a conciliação; e (b) instituições e procedimentos especiais, tais como os juizados de pequenas causas, os tribunais de vizinhança, os tribunais especiais para defesa dos consumidores, entre outros, para a garantia dos chamados novos direitos (MIRANDA, PETRILLO \& OLIVEIRA FILHO, 2004).

Promover a acessibilidade geral à justiça significa permitir que, nos tribunais de pequenas causas, o ajuizamento da ação seja realizado de forma simples, com poucas formalidades, com funcionários para assistir e orientar as partes e ajudar na definição das provas necessárias. A equalização das partes nos tribunais de pequenas causas pode ser alcançada quando dispensada a assistência de advogados, surgindo, em alguns casos, a figura de um juiz mais ativo e menos formalista. 
Em geral, a ênfase das cobranças, nessa instância do Judiciário, assenta-se ainda no direito individual. Apesar da classificação controversa do direito do consumidor sobre se é um direito individual ou coletivo, toma-se, neste trabalho, o enfoque segundo o qual é um direito que se move na fronteira entre o individual e o coletivo, como afirmado por diversos autores. Nesse sentido, este trabalho filia-se ao entendimento de processualistas italianos, como Capelleti e Zanetti (apud Tesheiner, 2005), que, de fato, classificam esse direito como multifacetado - coletivo, difuso, individual homogêneo ou social -, a depender do que se pede, ainda que, na maioria das demandas, os pedidos sejam introduzidos por questões privadas, de direito individual, com repercussões particulares para os envolvidos. Ademais, este trabalho endossa o ponto de vista de Grinover (2001), que classifica o direito do consumidor como de interesse social, mas não necessariamente coletivo.

\section{Os Juizados Especiais no Brasil}

O caminho brasileiro para o acesso à justiça teve as suas peculiaridades. A primeira iniciativa foi a do Ministério da Desburocratização nos anos oitenta e inspirou-se na experiência de Nova Iorque dos anos setenta. Lá, os juizados, criados em 1934, fizeram um considerável esforço para atender com mais presteza e eficiência a pequenas causas acumuladas com o tempo. A saída encontrada foi a implantação de juizados especiais com um microssistema judicial completo. Similarmente, em 1984 no Brasil, o Congresso Nacional aprovou a lei 7.244, que instituiu os Juizados Especiais de Pequenas Causas. Eram causas de todos os tipos que reclamavam, então, até 20 salários mínimos, limitadas às questões da justiça civil Esse modelo de juizado não era obrigatório para todos os estados. Quatro anos depois, essa lei foi incorporada ao texto da Constituição Federal de 1988; o Artigo 98, Inciso I, instituiu a obrigatoriedade da implementação dos juizados em todas as unidades da Federação. Essa inovação foi incluída nas estruturas do Poder Judiciário com o nome de Juizados Especiais. Em 1995, a lei 7.244 foi revogada pela lei 9.099, que trouxe como novidade a ampliação da ação dos juizados para a área criminal e a elevação do valor do teto das 
ações na área cível para 40 salários mínimos (art.3o, I). Seu espírito democratizante era voltado para a ampliação do acesso à justiça e encontra-se presente de forma clara no segundo artigo das Disposições Gerais da referida lei, que afirma: “O processo orientar-se-á pelos critérios da oralidade, simplicidade, informalidade, economia processual e celeridade, buscando, sempre que possível a conciliação ou a transação". (Art. 2º da Lei 9.099/95).

Pode-se dizer que a Constituição de 1988 avançou muito para promover a simplificação da ação dos juizados especiais em geral. No que diz respeito ao consumidor, houve o que pode ser avaliado como uma democratização do acesso à justiça na relação extremamente desigual das trocas no mercado econômico. As assimetrias nessas relações de troca foram equilibradas pela reformulação do direito do consumidor, que se apresenta agora tutelado constitucionalmente (LOPES, 2007). Ele foi alçado ao status de direito fundamental no art. $5^{\circ}$, XXXII, que reconhece a necessidade de proteção do consumidor como um princípio relevante na ordem econômica do país (ver Art. 170, V CF/88). Ao garantir o aperfeiçoamento de um microssistema de justiça, a Carta de 88 e toda a legislação infraconstitucional a partir dela promoveram a cidadania, ao construir uma forma de igualdade material provida por meio dos Juizados Especiais, que aproximam aquela parte da população antes distante do sistema judiciário e propiciam o desenvolvimento de uma cultura de vigilância dos direitos e uma mais diversificada participação cidadã na esfera pública.

O primeiro diagnóstico mais completo sobre o funcionamento desses juizados foi feito em 2006 pelo CEBEPEJ - Centro Brasileiro de Estudos e Pesquisas Judiciais (WATANABE, 2006; SADEK, 2006). Mostra as dificuldades enfrentadas para a implementação desse novo sistema, tais como: instalações físicas inadequadas, geralmente uma extensão das varas da justiça comum; localização, em grande parte dos estados brasileiros, em prédios anexos ao fórum da cidade, em péssimas condições; formação de uma má imagem que se disseminou entre os dirigentes dos tribunais sobre os Juizados Especiais, tidos como uma Justiça de segunda classe e para a qual se designavam, frequentemente, juízes considerados problemáticos; e número insuficiente de juízes alocados nos Juizados Especiais de todo o país em comparação com a justiça comum. Portanto, essa 
nova política da Justiça tem enfrentado tensões dentro do próprio Judiciário para uma adequada viabilização das próprias condições necessárias à democratização da justiça pleiteada por meio dos Juizados Especiais. Apesar disso, os dados revelam que existem tribunais em que os juizados são considerados como justiça de fato e sua importância é reconhecida, com juízes vocacionados e recursos de infraestrutura para um funcionamento adequado

Entretanto, eles não têm a mesma estrutura da justiça comum. Conforme o mesmo estudo acima indicado, os dados para 2003 mostram, por exemplo, que havia 7.609 magistrados para a justiça comum no Brasil e 751 para os juizados especiais cíveis (JEC). Portanto, os magistrados alocados para os JECs eram, comparativamente, apenas $9,86 \%$ do número alocado para a justiça comum. Em relação aos processos iniciados por 100.000 habitantes, os dados mostram que, nos juizados comuns do Brasil, houve 4.676,72/hab. e 1.993,86/ hab. nos JECs. Isto é, para apenas nove por cento de magistrados tem-se pouco menos da metade do número de processos iniciados, mostrando a exorbitância do volume proporcional de processos encaminhados para os JECs. O número de processos por magistrado informa que, para a justiça comum, são 946,45 e, para os JECs, são $2.242,96$, o que representa 2,36 vezes mais processos por juiz para os JECs. Quanto à taxa de congestionamento (o tempo acumulado para a permanência de um processo no sistema), a taxa nacional, conforme os dados do Supremo Tribunal Federal analisados pela pesquisa mencionada, mostra um tempo de 75,45 meses para a justiça comum e de 48,84 meses para os JECs, indicando que, a despeito de todos os problemas para a instalação e o funcionamento dos Juizados Especiais, eles, de fato, aceleram o andamento de processos de tal modalidade (SADEK, 2006).

\section{A institucionalização do Direito do Consumidor no Brasil e na Bahia.}

A grande marca da transição democrática no Brasil, a partir dos anos oitenta, foi o retorno do poder político aos civis, a reestruturação do Estado (que nem sempre resultou em descentralização) e a multiplicação dos padrões organizacionais da sociedade civil, 
ampliando a esfera pública e os espaços para a ação democrática. O processo da redemocratização pactuada entre o poder militar e a sociedade deu-se em função de uma estratégia política que permitiu pluralizar a participação e o acesso ao poder, com a mobilização popular em diversos níveis por meio de movimentos sociais. Assim, estabeleceram-se as bases para a reforma das normas jurídicas consolidadas na Constituição de 1988. Introduziram-se novos direitos voltados para a cidadania por meio da ampliação tanto dos direitos políticos e sociais como pela fundamentação dos direitos difusos, ditos de quarta geração, movidos por bandeiras de lutas sociais que cobrem desde questões ambientais até questões de gênero e de minorias étnicas, entre outros (IVO, 2001).

A luta por direitos que ampliem o escopo da cidadania, dignificando o indivíduo e a sua coletividade, fez parte, em última instância, da ação política voltada para a construção de instituições públicas e de uma sociedade civil que trouxessem estabilidade e perseverança nos propósitos democráticos para gerações futuras. É nesse sentido que os direitos humanos, no Brasil, passaram a integrar a pauta dos direitos humanos na escala mundial (direitos de gênero, de raça, da infância, do trabalho digno) e a compartir padrões de referência política e moral convergentes com a ideia de democracia nacional e sociedade democrática mundial (LOPES, 2007).

Não obstante, a redemocratização no Brasil ocorreu dentro de um paradoxo histórico. Isso porque esse período politicamente enriquecedor da reconstrução democrática nacional ocorreu concomitantemente ao ingresso do Brasil, e de outros países emergentes da América Latina ou de outros continentes, no processo de globalização. A globalização econômica e tecnológica privilegiou parâmetros de política econômica neoliberais e a centralidade do mercado acima do Estado e acima dos interesses de coletividades nacionais e de classe, dentro dos países e entre países do cenário econômico mundial. Uma das características do neoliberalismo foi justamente a flexibilização das relações entre capital e trabalho por meio da redução dos direitos sociais e redistributivos conquistados ao longo da formação, mutatis mutandis, do Estado de bem estar social em diversos países do Ocidente ao longo da segunda metade do século XX. Portanto, pode-se dizer que a expansão dos Direitos 
Humanos em anos mais recentes se deu por meio de uma tensão produzida na base mesma da formação dos direitos modernos: entre aqueles voltados para a consagração do sujeito-cidadão (o indivíduo em sua condição social de classe) e os direitos difusos. Enquanto direitos mais clássicos (do trabalhador, do sujeito político livre) fragilizaram-se, novos direitos inovadores, que se reportam a um sujeito difuso (a natureza, os animais, as gerações futuras, etc.), formaram-se e tornaram-se importantes tanto nas bandeiras de luta de movimentos sociais nacionais e transnacionais como nos discursos políticos oficiais (MILANI \& LANIADO, 2006). O direito do consumidor tomou corpo na conjuntura dessas relevantes e controversas mudanças ocorridas nas últimas décadas no Brasil e no mundo.

O direito do consumidor está a representar uma grande conquista nas relações desiguais do mercado capitalista, entre consumidor e empresa, mas ele também representa a tensão entre os tipos de direitos referidos anteriormente. Isso porque, após quase duas décadas de neoliberalismo econômico e a consolidação da força do mercado na economia (ainda que o Estado brasileiro sempre tenha mantido a sua capacidade de regulamentação e intervenção), vê-se uma maior concentração da riqueza no topo da pirâmide social e uma redução da pobreza extrema na base dessa pirâmide, propiciada por políticas sociais compensatórias e focadas ${ }^{1}$.

É na esteira da democratização brasileira, da capacidade de mobilização da sociedade civil e da intensificação da demanda por direitos de outra ordem que surge a consciência sobre o direito do consumidor, para regular de forma mais transparente as relações desiguais entre as partes naquelas relações de troca específicas do mercado: o consumo. O Idec é a expressão institucional dessas mudanças e paradoxos.

1 A mais importante dessas políticas é o Programa Bolsa Família, um programa de política social focada nos pobres e muito pobres, que conjuga diversos programas de assistência do Estado, iniciados no governo de Fernando Henrique Cardoso, fundidos e consolidados no governo de Luis Inácio Lula da Silva. O Programa congrega hoje pouco mais de 12 milhões de famílias que, em troca de um auxílio mensal variável conforme o número de filhos, devem mantê-los na escola (http:// www.mds.gov.br/bolsafamilia, consultado em 03.08.2010. Na realidade, a bolsa família não é um direito do cidadão em relação ao Estado, mas um programa de governo de caráter compensatório para combater a pobreza. 
O Idec, Instituto Brasileiro de Defesa do Consumidor ${ }^{2}$ - órgão engajado na luta para reconhecimento e defesa dos direitos consumeristas no Brasil -, desde sua fundação em 1987, reconhece, no "Guia de responsabilidade social para o consumidor" (2004), que as primeiras manifestações relativas ao direito do consumidor, no Brasil, abrem-se com as lutas contra a carestia, tal como os movimentos da Marcha da Fome (1931), da Marcha da Panela Vazia (1953), o Protesto Contra o Alto Custo de Vida (agosto de1963) e o primeiro boicote à carne em 1979. Desde 1962, o governo começou, timidamente, a regular a distribuição de produtos para o consumo. A criação da Vigilância Sanitária é um instrumento legal para tornar mais seguro o consumo de produtos de origem animal; o Inmetro, Instituto Nacional de Metrologia, Normalização e Qualidade Industrial, foi criado no início da década de 70, para fiscalizar a qualidade e segurança dos produtos industrializados. Nesse mesmo período, surgem as primeiras organizações de defesa do consumidor no Rio de Janeiro, em Curitiba, Porto Alegre e Brasília e o primeiro órgão público de proteção e defesa do consumidor, o Procon de São Paulo. Com a redemocratização e a crescente organização da sociedade civil na década de oitenta, no país, a Constituição promulgada em 1988 amplia o seu escopo de democratização dos direitos e das suas representações sociais, institui a condição jurídica de defesa coletiva dos interesses difusos e incorpora os direitos do consumidor, após o que é criado o Conselho Nacional de Defesa do Consumidor.

O Idec, como uma associação de consumidores sem fins lucrativos, desempenhou papel importantíssimo na luta pela criação de uma lei específica para garantir o direito do consumidor, produzida em 1990: o Código de Defesa do Consumidor brasileiro, que entra em vigor em 1991. O Código surge em meio a uma mobilização social intensa de um mercado de consumo industrial de massa bastante ampliado, apesar das desigualdades de renda e riqueza no Brasil. Até a Constituição Federal de 1988, qualquer matéria relativa ao consumidor era apreciada nas disposições do Código Civil ou em leis esparsas.

2 Informações disponíveis em: http://www.idec.org.br/vitorias_listar.asp. Consultado em 18/03/2007. 
A defesa do consumidor, como já mencionado, foi elevada à categoria de princípio constitucional da ordem econômica (art. 170, $\mathrm{V}$ da $\mathrm{CF}$ ) e tem, de certa forma, alguma vantagem sobre os outros princípios que lhes são equivalentes. Entretanto, o Estado precisou efetivar um sistema integrado através dos órgãos que formam hoje o Sistema Nacional de Defesa do Consumidor. Criado na década de 90, o sistema inclui o Procon, o Inmetro, as Promotorias de Justiça, as Defensorias Públicas, as Delegacias do Consumidor e os Juizados Especiais Cíveis, além de associações de consumidores reunidas no Fórum Nacional de Entidades Civis de Defesa do Consumidor, presidido pelo Idec. O Idec, até hoje, exerce o importante papel de fiscalizar e defender os direitos do consumidor, ao instruir e conscientizar os indivíduos sobre a ética nas relações de consumo (LOPES, 2007).

A especificidade histórico-política dá o contorno do contexto de implantação dos JECs na Bahia, onde a cultura política regional - tradicional, centralizadora e modernizadora ao mesmo tempo - imprime um modo particular de efetivação de um preceito constitucional e dos recursos institucionais mobilizados para sua implementação. A despeito dos limites e avanços no processo de ampliação do campo democrático e do caráter centralizador e personalista do carlismo na política local (DANTAS NETO, 2003), a Bahia foi pioneira, entre os Estados brasileiros, na implementação dos novos direitos constitucionais, ao implantar os Juizados Especiais. De fato, a Bahia saiu na frente para regulamentar os direitos do consumidor. Desde dezembro de 1985, foram criados os Juizados Especiais de Pequenas Causas, instituídos pela Lei Estadual no 4.630, isto é, pouco mais de um ano após a lei Federal no 7.244 de 1984, que previa a criação desses Juizados. Posteriormente, em 1992, dois anos após a publicação do Código de Defesa do Consumidor, a Bahia criou os Juizados Especiais Cíveis de Defesa do Consumidor (JECDC), com a Lei Estadual no 6.371 de março de 1992. Em seguida, com a Lei Estadual no 7.033 de fevereiro de 1997, o governo baiano reorganizou os Juizados Especiais Cíveis e Criminais no Estado e criou os Juizados Modelos, em apoio aos Juizados Especiais de causas comuns e do consumidor já existentes. Contudo, somente em 1999 foram inaugurados o Primeiro e o Segundo Juizado Especial Cível de Defesa do Consumidor - JECDC. 


\section{Os Juizados de Defesa do Consumidor na Bahia.}

A capital baiana conta com diversos órgãos de defesa do consumidor, tais como: o Procon (Proteção e Defesa do Consumidor) - são cinco na cidade, o Codecon (Coordenação de Defesa do Consumidor), o Deacon (Departamento de Assistência do Consumidor), o Ceacon (Centro de Apoio Operacional às Promotorias de Justiça do Consumidor), a Delegacia de Defesa do Consumidor, a Comissão de Defesa e Orientação do Consumidor da OAB-BA e, finalmente, a Promotoria de Justiça do Consumidor. Porém, são os dois Juizados Especiais Cíveis de Defesa do Consumidor e mais seus dois órgãos extensivos de apoio que recebem o maior número de queixas consumeristas e tratam exclusivamente da relação de consumo.

Como já mencionado, o recorte empírico deste trabalho enfoca uma pesquisa realizada em 2006/2007 sobre a visão dos juízes que lidam com o direito do consumidor a partir do microssistema dos Juizados Especiais implantados no Estado. Além disso, o estudo contempla o próprio desempenho dos juizados no atendimento às demandas dos consumidores ${ }^{3}$. Isto é, foram investigadas as condições reais de assistência jurídica, considerando as questões de eficiência, efetividade, reconhecimento dos direitos, produção de novos direitos e os valores de cultura política que resultam dessa relação entre Estado e cidadão.

Aprofundar o entendimento desse tema demandou identificar as possíveis contribuições desses órgãos para a justiça social, igualdade, cidadania e a superação de práticas tradicionais de acomodação do cidadão no âmbito da defesa dos direitos no cotidiano. O Primeiro Juizado Especial Cível de Defesa do Consumidor do bairro dos Barris foi inaugurado em 1999, com quatro conciliadores e três juízes. Em face do grande contingente de processos, em 2003 passou a contar com um órgão de apoio, o NAJ, Núcleo de Apoio Judicial, localizado na Baixa dos Sapateiros, que contava, em 2007, com quatro conciliadores e dois juízes. O Segundo Juizado Especial Cível de Defesa do Consumidor, inaugurado em 1999 no bairro de Brotas, está localizado hoje no bairro do Iguatemi e contava então com cinco conciliadores

3 Dados coletados por Saskya Miranda Lopes. 
e quatro juízes. Em face da grande demanda de causas consumeristas, inaugurou em 2002 um órgão auxiliar de Extensão do Juizado Modelo, localizado na Faculdade Jorge Amado, que contava então com quatro conciliadores e dois juízes. Portanto, um total de onze juízes e dezessete conciliadores na época da pesquisa.

Apesar das imprecisões das informações disponíveis e identificadas durante a pesquisa, o trabalho de campo, os relatórios estatísticos existentes, ainda que simples, permitiram identificar a movimentação e o volume de ações iniciadas e resolvidas pelos juizados, seja na fase inicial (com os acordos perante os conciliadores) ou posterior (com sentenças julgadas em seu mérito pelos juízes) no decorrer dos últimos cinco anos. Foi possível entrecruzar esses dados com o movimento de aumento de fluxo aos juizados em decorrência de problemas de prestação de serviços ao consumidor, como aconteceu entre os anos de 2003 e 2004, com a questão relativa ao atendimento aos associados dos planos de saúde ${ }^{4}$. Ou ainda com dados sobre as ações do próprio Judiciário baiano, com o objetivo de atualizar a pauta de audiências ou proferir sentenças de processos que há muito tempo aguardavam decisão. As informações estão agregadas nas tabelas a seguir, para demonstrar a relação existente entre: a) o volume de processos iniciados por ano em cada juizado e os processos concluídos; b) o número de audiências de conciliação $0^{5}$ e acordos que foram realizados por juizado em cada ano; c) o número de audiências de instrução ${ }^{6}$ (com o juiz) que foram

4 A resistência dos planos de saúde em conceder o reajuste pleiteado pelos médicos vinculados aos planos gerou a suspensão do atendimento de vários consumidores conveniados. Em consequência, os consumidores foram orientados a obter liminares na Justiça. Esse movimento que levou centenas de pessoas aos JECDCs em busca dos seus direitos.

5 As audiências de conciliação são obrigatórias por lei para os JECs, tanto de causas comuns quanto para as consumeristas, e visam a um entendimento ou acordo entre as partes litigantes, antes mesmo de se entrar no mérito da razão e do direito violado, ou antes de se apresentar a lide propriamente dita ao juiz. (Lei 9.099 de 1995, art. 21 e seguintes).

6 Audiência de instrução é aquela que vem em sequência a uma audiência de conciliação frustrada; é quando se instrui o processo, apresentando as provas existentes, ouvem-se as versões das partes quanto à lide e colhe-se o depoimento das testemunhas, após o que o juiz decide quanto à veracidade da demanda (Lei 9.099 de 1995, art. 27 e seguintes). 
realizadas e o de sentenças que foram proferidas, e d) os tipos de demandas sociais encaminhadas aos JECDCs.

A Tabela 1 apresenta o número de processos iniciados e concluídos no período compreendido entre o ano de 2000 e 2005 em cada juizado e sua extensão em Salvador. É preciso observar que a proposta idealizada para os JECDCs, de iniciarem e concluírem um processo em um período inferior a um ano, não tem sido alcançada. Muitos dos processos iniciados só são concluídos dois, três ou até quatro anos depois. A diferença entre o número de processos iniciados em um ano para o número de processos concluídos no mesmo ano é explicitada na Tabela 1. É importante esclarecer que a conclusão de um processo, para o Direito Processual (e para as estatísticas aqui apresentadas), pode ocorrer de diversas formas; além disso, deve-se levar em conta que o JECDC pode se declarar o órgão não competente para uma determinada demanda, ou mesmo pode ocorrer a própria desistência da ação por parte do demandante.

Tabela 1 - Processos iniciados e concluídos (2000 a 2005)

\begin{tabular}{|l|c|c|c|c|c|c|c|c|c|c|c|c|}
\hline \multirow{2}{*}{ Juizados } & \multicolumn{2}{|c|}{2000} & \multicolumn{2}{c|}{2001} & \multicolumn{2}{c|}{2002} & \multicolumn{2}{c|}{2003} & \multicolumn{2}{c|}{2004} & \multicolumn{2}{c|}{2005} \\
\cline { 2 - 12 } & Início & Fim & Início & Fim & Início & Fim & Início & Fim & Início & Fim & Início & Fim \\
\hline $\begin{array}{l}1^{\circ} \text { JECDC - } \\
\text { Barris }\end{array}$ & 6577 & 4904 & 5796 & 3750 & 5947 & 3447 & 7416 & 6027 & 6722 & 4004 & 2210 & 4120 \\
\hline $\begin{array}{l}2^{\circ} \text { JECDC - } \\
\text { Brotas }\end{array}$ & 4722 & 3783 & 4582 & 3647 & 6723 & 6035 & 9354 & 6767 & 7779 & 5227 & 5251 & 4596 \\
\hline $\begin{array}{l}\text { EXT.1 }{ }^{\circ} \text { JECDC } \\
- \text { NAJ" }\end{array}$ & - & - & - & - & - & - & 1958 & 902 & 4493 & 3537 & 2664 & 4538 \\
\hline $\begin{array}{l}\text { EXT.2 }{ }^{\circ} \text { JECDC } \\
- \text { JA }^{*}\end{array}$ & - & - & - & - & - & - & - & - & 4441 & 2433 & 3328 & 2180 \\
\hline
\end{tabular}

*Inaugurado em 20/08/2003.

Fonte: Dados do Tribunal de Justiça da Bahia. Coletados em 2006/2007. Tabela: criação própria.

Na tabela acima, pode-se observar que, em 2000, os JECDCs dos Barris e de Brotas, com apenas um ano de inaugurados, contavam juntos com 11.299 processos iniciados, e fecharam o ano com 8.687 processos concluídos. Em 2001, houve uma ligeira queda 
da demanda, para 10.378 processos iniciados e 7.397 processos concluídos. Em 2002, o Segundo JECDC de Brotas ultrapassou em número de processos o Primeiro JECDC dos Barris: são 6.723 iniciados e 6.035 concluídos no $2^{2}$ JECDC de Brotas, para 5.947 iniciados e 3.447 concluídos no Primeiro JECDC dos Barris, o que demonstra o aumento da afluência de consumidores para o Segundo JECDC de Brotas.

Em 2003, foi criada a Extensão do Primeiro JECDC dos Barris - o NAJ -, que, em quatro meses de atuação, recebeu quase dois mil processos. Sua ação como órgão de extensão se confirmou com o número de processos iniciados em 2004 - mais que o dobro de 2003. Mesmo que os números das estatísticas de 2003 e 2004 tenham sofrido uma alta considerável em virtude das liminares contra os planos de saúde, os dados revelam uma confiança do consumidor nos Juizados de Defesa do Consumidor como solução para seus problemas e a perseguição dos seus direitos, uma situação que se expressa no ano de 2003, com o maior número de processos iniciados nos JECDCs de Brotas e dos Barris para o período em tela.

Em 2004 a extensão do Segundo JECDC de Brotas, situada na Faculdade Jorge Amado, que atende exclusivamente a causas consumeristas, fechou o ano com 4.441 processos iniciados e 3.537 processos concluídos. Em 2005 o Primeiro JECDC dos Barris, por falta de condições de funcionamento e de recursos humanos, foi obrigado a passar alguns meses sem receber queixas; fechou o ano com o menor número de processos iniciados desde sua criação 2.210 processos.

O desempenho de cada juizado em relação ao andamento dos processos pode ser descrito pelas fases processuais que seguem um processo e são as seguintes: dar entrada a uma queixa; marcar uma audiência de conciliação; em caso de acordo, o processo é conciliado e concluído; caso contrário, ele segue para a audiência de instrução, quando o juiz forma seu juízo de convencimento e profere a sentença de mérito, resolvendo a questão. São essas fases que se observam em números nas tabelas a seguir, ano a ano, para cada juizado. 
Tabela 2 - Desempenho do Primeiro JECDC - Barris (2000-2005)

\begin{tabular}{|l|c|c|c|c|c|c|c|}
\hline Processos & 2000 & 2001 & 2002 & 2003 & 2004 & 2005 & TOTAL \\
\hline Iniciados & 6577 & 5796 & 5947 & 7416 & 6722 & 2210 & 34668 \\
\hline Sessão de conciliação & - & - & - & - & 1400 & 426 & 1826 \\
\hline Conciliados & 1849 & 1478 & 1295 & 2101 & 627 & 590 & 7940 \\
\hline Audiências de instrução & 2693 & 2340 & 2733 & 4127 & 3825 & 4861 & 20579 \\
\hline $\begin{array}{l}\text { Sentenças de mérito e } \\
\text { embargo }\end{array}$ & 2130 & 1569 & 1964 & 2000 & 2991 & 5009 & 15663 \\
\hline
\end{tabular}

Fonte: Dados do Tribunal de Justiça da Bahia. Coletados em 2006/2007. Tabela: criação própria.

O Primeiro JECDC dos Barris, até 2004, não realizava conciliações em sua sede, porque elas ocorriam nos SACs - Serviços de Atendimento ao Cidadão. Posteriormente, elas foram direcionadas para o juizado, seja para homologar as conciliações, seja para a realização das audiências de instrução. De qualquer forma, observa-se que os números de audiências de instrução ao longo dos anos são menos da metade da quantidade de processos iniciados, salvo nos anos de 2003, 2004 e 2005, em virtude da promoção de mutirões de audiências e a vedação de recebimento de queixas no ano de 2005. O resultado foi o maior número de atendimentos dos últimos cinco anos desse juizado: 4.861 audiências de instrução e 5.009 sentenças. Mais significativo é o número total de sentenças, 15.663, que é menos da metade dos processos iniciados durante todo o período, 34.668 processos. Ressalta-se que nem todas essas sentenças são necessariamente de processos diferentes e muito menos decisões que elucidam os problemas apresentados aos juizados. A perspectiva melhora se somarmos ao número de sentenças o número de acordos, 7.940, o que perfaz 23.603 processos findos com alguma resposta jurisdicional.

Para o Segundo JECDC de Brotas, os dados sintetizados na Tabela 3 mostram o desenho da atuação do órgão para o período. 
Tabela 3 - Desempenho do Segundo JECDC-Brotas - anos 2000-2005.

\begin{tabular}{|l|c|c|c|c|c|c|c|}
\hline Processos & 2000 & 2001 & 2002 & 2003 & 2004 & 2005 & TOTAL \\
\hline Iniciados & 4722 & 4582 & 6723 & 9354 & 7779 & 5251 & 38411 \\
\hline Sessão de conciliação & - & - & - & - & 9348 & 6426 & 15774 \\
\hline Conciliados & 1848 & 1601 & 2059 & 2530 & 1554 & 1369 & 10961 \\
\hline $\begin{array}{l}\text { Audiências de } \\
\text { instrução }\end{array}$ & 1722 & 2077 & 3023 & 4648 & 2905 & 4694 & 19069 \\
\hline $\begin{array}{l}\text { Sentenças de mérito } \\
\text { e embargo }\end{array}$ & 887 & 888 & 2718 & 2655 & 2737 & 3646 & 13531 \\
\hline
\end{tabular}

Fonte: Dados do Tribunal de Justiça da Bahia. Coletados em 2006/2007. Tabela: criação própria.

O Segundo JECDC de Brotas também não realizava conciliações em sua sede; passou a fazê-lo a partir do ano de 2004, com um número de conciliações significativo: 9.348. No entanto, teve poucos resultados, logrando apenas 1.554 acordos para esse ano. O número total de respostas, sentenças e conciliações dos juizados frente às demandas apresentadas no JECDC de Brotas, 24.492, é um pouco maior que o número total obtido pelo JECDC dos Barris, 23.603, mas ainda é bem menor do que o número de processos iniciados durante os cinco anos, que foi de 38.411 processos. Merece observação também o número de audiências de instrução realizadas, sempre abaixo da metade do número de processos iniciados a cada ano, salvo em 2005, quando o juizado foi beneficiado por um mutirão de audiências. Uma das explicações para esse baixo número de audiências de instrução e sentenças está na diminuição gradativa da quantidade de juízes disponibilizados na época em relação ao previsto para esse juizado. Apesar de constar, nas publicações do Diário Oficial do Poder Judiciário, a lotação de quatro juízes para esse juizado, por motivos diversos e relevantes, isso não ocorria. No mês de novembro de 2006, por exemplo, o Segundo JECDC de Brotas ficou com apenas um juiz responsável por todos os processos, o que tornou impossível viabilizar as responsabilidades do órgão. Os órgãos de extensão dos juizados têm um período menor de existência, mas apresentaram números bastante expressivos, como se pode ver nos dados da Tabela 4 a seguir sobre o órgão de extensão do JCDC dos Barris. 
Tabela 4 - Desempenho da extensão do JCDC - NAJ* (2000-2005)

\begin{tabular}{|l|c|c|c|c|c|c|c|}
\hline Processos & 2000 & 2001 & 2002 & 2003 & 2004 & 2005 & TOTAL \\
\hline Iniciados & - & - & - & 1958 & 4441 & 3328 & 9727 \\
\hline Sessão de conciliação & - & - & - & - & 5604 & 3747 & 9351 \\
\hline Conciliados & - & - & - & 413 & 1455 & 1809 & 3677 \\
\hline Audiências de instrução & - & - & - & 461 & 1889 & 2757 & 5107 \\
\hline $\begin{array}{l}\text { Sentenças de mérito e } \\
\text { embargo }\end{array}$ & - & - & - & 560 & 1030 & 1826 & 3416 \\
\hline
\end{tabular}

Fonte: Dados do Tribunal de Justiça da Bahia. Coletados em 2006/2007. Tabela: criação própria. "Inaugurado em 20/08/2003

O NAJ foi inaugurado em agosto de 2003 como Extensão do Primeiro JECDC dos Barris para desafogar a demanda desse Juizado e ser mais uma opção de acesso à justiça para os consumidores. No primeiro ano, não registrou audiências de conciliação, pois os processos vinham do JECDC dos Barris; nos anos seguintes, tanto as audiências de instrução quanto as sentenças apresentam uma boa média de atendimento em relação aos outros Juizados vistos até aqui. No total do período, quase se igualou o número de processos iniciados, 9.727, com o número de conciliações, 9.351. Contudo, o número de sentenças continuou sendo baixo, apenas 3.416, um indício da necessidade de mais juízes em cada órgão para atender à demanda. Na Tabela 5 abaixo, apresentam-se os dados do órgão de extensão do JECDC de Brotas.

Tabela 5 - Desempenho da extensão do JECDC-JA - anos 2000-2005

\begin{tabular}{|l|c|c|c|c|c|c|c|}
\hline Processos & 2000 & 2001 & 2002 & 2003 & 2004 & 2005 & TOTAL \\
\hline Iniciados & - & - & - & - & 4493 & 2664 & 7157 \\
\hline Sessão de conciliação & - & - & - & - & 2784 & 4103 & 6887 \\
\hline Conciliados & - & - & - & - & 1054 & 844 & 1898 \\
\hline Audiências de instrução & - & - & - & - & 1000 & 2441 & 3441 \\
\hline $\begin{array}{l}\text { Sentenças de mérito e } \\
\text { embargo }\end{array}$ & - & - & - & - & 833 & 1021 & 1854 \\
\hline
\end{tabular}

Fonte: Dados do Tribunal de Justiça da Bahia. Coletados em 2006/2007. Tabela: criação própria. 
Apesar de funcionar desde 2002, inclusive com causas consumeristas, os números estatísticos da Extensão do Segundo JECDC de Brotas, situado na Faculdade Jorge Amado, só informam dados seguros a partir de 2004, quando o órgão passou a processar exclusivamente ações de direito do consumidor. Mesmo quando se consideram os altos números de queixas, 4.493 no ano de 2004, um ano atípico para todos os juizados, os números de sentenças e processos conciliados somados correspondem a 1.887 processos concluídos, com análise de mérito e com uma boa proporção de audiências de instrução e sentenças proferidas, mostrando somente 167 sentenças a menos que a quantidade de audiências de instrução. No total do período, contudo, o número de processos conciliados e sentenciados foi de 3.752 , pouco mais da metade do total de processos iniciados, 7.157 .

A partir de 2005, o Supremo Tribunal Federal, órgão máximo da organização judiciária nacional, passou a exigir que os relatórios dos juizados espelhassem o volume de processos classificados pela identificação das empresas rés; são esses os dados compilados na Tabela 6; eles servem para melhor identificar de que se queixam mais os consumidores baianos.

Na tabela, é possível observar que o maior número de ações dos consumidores baianos, em 2005, foi contra as instituições financeiras, com 1.842 casos; em segundo lugar ficaram as empresas de telefonia fixa, com 1.657 ações. A liderança das queixas contra as instituições financeiras deve-se, em boa parte, à expressiva reação dos aposentados aos empréstimos realizados junto a essas empresas $^{7}$. Em terceiro lugar na lista, encontram-se as ações contra as administradoras de cartões de crédito, com 1551 casos. Seguem-se os planos de saúde, com 1.276 ações, e depois os estabelecimentos comerciais e fabricantes, com 1.270 ações, um conjunto que ilus-

7 Durante o ano de 2005, vários bancos, inclusive de outros Estados, investiram na captação de um novo filão de cliente, o aposentado. Ofereceram linhas de crédito com juros diferenciados, mas não deixavam claro o suficiente os juros totais desses empréstimos ou as formas de reajuste do saldo devedor, que só eram identificados quando os consumidores viam suas aposentadorias reduzidas pelas prestações para os pagamentos dos empréstimos. 
tra, entre outros, a lista dos interesses mais contestados na Justiça naquele ano. O item "outros", com 1.533 ações, agrupa demandas diversas que ainda estavam sem classificação específica à época.

Tabela 6 - Tipos de demandas dos JECDCs de Salvador - ano 2005.

\begin{tabular}{|l|c|c|c|c|c|}
\hline Processos & $\begin{array}{c}\text { 1 JECDC- } \\
\text { Barris }\end{array}$ & $\begin{array}{c}\text { 2 }^{\circ} \text { JECDC- } \\
\text { Brotas }\end{array}$ & $\begin{array}{c}\text { EXT. } \\
\text { JECDC-J.A }\end{array}$ & $\begin{array}{c}\text { EXT. } \\
\text { JECDC-NAJ }\end{array}$ & Total \\
\hline Instituição financeira & 128 & 797 & 444 & 473 & 1842 \\
\hline Empresa de telefonia fixa & 543 & 515 & 237 & 362 & 1657 \\
\hline $\begin{array}{l}\text { Administradora de } \\
\text { cartões de crédito }\end{array}$ & 185 & 889 & 229 & 248 & 1551 \\
\hline Outras & 594 & 154 & 53 & 732 & 1533 \\
\hline Seguro de plano de saúde & 75 & 743 & 281 & 177 & 1276 \\
\hline $\begin{array}{l}\text { Fabricante e/ou } \\
\text { estabelecimento } \\
\text { comercial }\end{array}$ & 216 & 507 & 105 & 442 & 1270 \\
\hline $\begin{array}{l}\text { Empresa de telefonia } \\
\text { móvel }\end{array}$ & 157 & 399 & 241 & 280 & 1077 \\
\hline Prestação de serviços & 23 & 430 & 318 & 205 & 976 \\
\hline $\begin{array}{l}\text { Administradora de } \\
\text { consórcio }\end{array}$ & 81 & 222 & 58 & 77 & 438 \\
\hline Instituição de ensino & 26 & 174 & 109 & 88 & 397 \\
\hline $\begin{array}{l}\text { Companhia de energia } \\
\text { elétrica }\end{array}$ & 36 & 167 & 81 & 105 & 389 \\
\hline $\begin{array}{l}\text { Empresa de água e } \\
\text { saneamento }\end{array}$ & 28 & 164 & 43 & 107 & 342 \\
\hline Companhia seguradora & 118 & 66 & 47 & 29 & 260 \\
\hline $\begin{array}{l}\text { Serviço de proteção ao } \\
\text { crédito }\end{array}$ & 0 & 24 & 19 & 3 & 46 \\
\hline
\end{tabular}

Fonte: Dados do Tribunal de Justiça da Bahia. Coletados em 2006 e 2007. Tabela: criação própria. 


\section{Percepção dos juízes sobre a institucionalização do Direito do Consumidor}

Os dados sobre a percepção dos juízes em relação aos JECDCs foram registrados por meio de um questionário com perguntas abertas e fechadas aplicado a juízes ${ }^{8}$ desse microssistema da justiça baiana. Metodologicamente, decidiu-se por orientar a pesquisa para os atores do sistema, porque o tema do trabalho é a institucionalização dos direitos consumeristas e, portanto, os envolvidos em sua execução têm um papel expressivo na função da aplicação da lei e de viabilizar o usufruto desses direitos. Em seguida, são apresentadas as análises das questões mais expressivas sobre o papel dos juizados de execução do direito do consumidor a partir da fala dos juízes. A análise está ordenada em sete categorias sobre o entendimento do tema: a eficiência, a efetividade da legislação, o consumidor, as decisões sobre esses direitos, a educação, a cultura política e a percepção dos juízes que atuam no setor.

A - A Eficiência dos procedimentos nos JECDCs. Inquiridos sobre os procedimentos legais, os passos do processo para implementação dos direitos, cinco dos entrevistados afirmaram que são os melhores e mais avançados, pois estão em consonância com os princípios da celeridade e economia processual, da oralidade e da gratuidade, resultando em maior acessibilidade dos consumidores aos juizados. No entanto, esse avanço do sistema judiciário se de-

8 Quando da pesquisa de campo, eram onze juízes que compunham os dois Juizados Especiais Cíveis de Defesa do Consumidor (JECDCs) da Bahia e seus dois órgãos de extensão. Sete deles aquiesceram em participar da pesquisa. Ainda que, em termos absolutos, o número pareça pequeno, ele representa mais da metade dos juízes desse microssistema do Judiciário e sustenta empiricamente este estudo de caso. São duas mulheres e cinco homens, entre 30 e 61 anos, que responderam ao questionário semiaberto. Cinco formados pela Universidade Federal da Bahia (UFBA) e dois pela Universidade Católica de Salvador (UCSAL). Seis têm pós-graduação em Direito, contudo apenas três deles na área dos direitos difusos, coletivos ou consumeristas. Seis atuam há mais de 15 anos como juízes, e quatro atuam há mais de 5 anos como juízes de matéria consumerista. Três ingressaram nos JECDCs por nomeação e outros três por motivação pessoal, tal como afinidade com a matéria ou com a proposta do modelo de uma justiça mais célere e simplificada para a população comum; somente um dos entrevistados escolheu os juizados para diversificar seus conhecimentos e ter experiência nas diversas áreas do Direito. 
para com a deficiência das condições materiais e físicas, sobretudo a carência de recursos humanos (juízes e pessoal de apoio). Esse problema foi também identificado pela Secretaria de Reforma do Judiciário, na pesquisa realizada pelo Centro Brasileiro de Estudos e Pesquisas Judiciais em Juizados Especiais de todo o país, mencionada anteriormente.

B - A legislação versus a efetividade dos direitos. Quanto a se fazerem cumprir as decisões dos juizados e, de fato, viabilizar a efetivação dos direitos em tela, os depoimentos abordam quatro tópicos diferentes. Somente um juiz considerou necessário haver uma lei mais rígida para uma maior efetividade dos direitos consumeristas, que obrigasse o cumprimento das decisões por parte dos condenados. Um depoimento informou que seria relevante a presença de um advogado acompanhando o consumidor no julgamento, no juizado. Outros dois juízes consideraram que a legislação é boa, mas não é mais eficiente devido à falta de estrutura dos órgãos envolvidos. Finalmente, para três juízes, é preciso haver uma conscientização dos cidadãos quanto ao cumprimento dos seus deveres; isso porque, se as obrigações legais - na maioria autoaplicáveis - fossem cumpridas, não existiria sequer a superlotação nos JECDCs. O que reforça a ideia de uma fraca relação de reciprocidade entre cidadãos e instituições na sociedade nas relações de consumo; pode-se dizer que há um grau de negação das obrigações.

C - Os consumidores conhecem seus direitos? Os entrevistados dividiram-se quanto a essa questão. Dentro de uma perspectiva positiva, três percebem que, hoje, os demandantes se informam mais e sabem quais são os seus direitos como consumidores. Inversamente, uma resposta informou que os consumidores não sabem expressar os seus direitos. Em uma posição intermediária, três juízes entendem que esse conhecimento varia de acordo com o nível socioeconômico do indivíduo; informaram ainda que certos demandantes não percebem os possíveis desdobramentos de sua ação na justiça para a coletividade, e que estão ali apenas para resolver um problema pessoal. Pode-se dizer, à luz dos depoimentos, que é possível perceber, nas demandas do consumidor-cidadão aos juizados, uma predominância de questões de interesse privado, mas que têm uma forte dimensão coletiva, ainda que isso nem sempre 
esteja claro para o consumidor; isso porque suas queixas se referem a serviços públicos que só podem ser providos de forma coletiva (luz, água, sistema de saúde, políticas financeiras para aposentados etc.). O demandante recorre aos Juizados Especiais para exigir o cumprimento desses serviços que, geralmente, o Estado transferiu para a iniciativa privada por conta da implementação das diretrizes neoliberais na economia. Como se pôde ver na Tabela 6 , as queixas se orientam mais para cobrar a eficiência dos serviços regulamentados pelo poder público, providos por empresas privadas concessionárias em relação a: saúde, água, energia, telefonia, etc.. Essa demanda por uma justiça célere e gratuita por parte das classes populares na esfera consumerista se integra àquelas demandas encaminhadas à Justiça na esfera dos direitos sociais mal providos pelo Estado (TEIXEIRA \& LANIADO, 2004).

D - As decisões dos JECDCs e a produção de novos direitos. No que tange à concepção de uma justiça dinâmica, no sentido de Heller (1998), os entrevistados não identificaram, nos direitos do consumidor, uma possibilidade de criação e ampliação de novos direitos propriamente. Quatro entenderam que a jurisprudência dos Juizados Especiais tem contribuído para dar conhecimento aos indivíduos da existência de direitos que lhes pertinem. Pois, quando os consumidores percebem que foi reconhecido um determinado direito em última instância no judiciário (uma causa já ganha), todos os outros consumidores com demanda semelhante se mobilizam para fazer valer esse mesmo direito. Das discussões em torno dessas demandas e do resultado alcançado nasce a possibilidade de avaliação das normas pelos indivíduos e de sua aceitação ou rejeição. Com uma visão mais crítica, outros três dos entrevistados vislumbraram a existência de um movimento político interno em torno da autonomia dos JECDCs. Esse movimento permitiria que as jurisprudências, as súmulas, as discussões e os enunciados firmados nos congressos e fóruns jurídicos alçassem à condição de novos direitos, numa aproximação com o direito dinâmico norte-americano, que produz inovações legais a partir de decisões judiciais. Os depoimentos informaram que, mesmo sem ser possível identificar essas súmulas com novos direitos materiais, sem dúvida os consumidores, de alguma forma, ganhariam com tais 
enunciados e súmulas, que poderiam ser identificados como uma nova forma de direito subjetivo, processual, viabilizador de procedimentos mais céleres e simples, de acordo com o próprio objetivo da legislação dos Juizados Especiais Cíveis (LOPES, 2007). A citação a seguir exemplifica uma crítica e uma constatação dos resultados positivos decorrentes da autonomia dos JECDCs em prol de uma sociedade mais equânime na distribuição de justiça (social) por meio das demandas encaminhadas aos juizados especiais:

Quando a legislador criou esse sistema, quase que jogou um barro na parede para ver se colava; colou, e talvez a própria estrutura de poder não estivesse preparada para que este barro tivesse colado tão bem. Por que eu digo isso? Porque se você verificar que quase toda a produção jurídica do juizado não tem controle de nenhum outro tribunal, [...] isso acarretou uma jurisprudência muito mais de ponta, $[. .$.$] o jurídico está botando pra quebrar aqui em baixo e$ dando ao direito do consumidor uma forma mais justa e mais rápida, mais célere. ( Entrevistado 3 ).

E-A educação para a vida coletiva. A percepção de seis dentre os sete entrevistados é de que os JECDCs educam os indivíduos para a vida na coletividade política à qual pertencem. Essa visão é interessante quando comparada com o grau diferenciado de compreensão por parte dos demandantes sobre os seus próprios direitos constatado pelos juízes entrevistados, conforme foi informado no item " $\mathrm{C}$ - Os consumidores conhecem seus direitos?” Depreende-se que, independentemente da maior ou menor informação ou compreensão dos próprios direitos ou da classe social do demandante, há algum nível de entendimento de que a procura dos Juizados Especiais para exigir, participar e enfrentar o outro é, sim, educativa para todos os envolvidos, inclusive para o provedor de bens e serviços na esfera nacional ou multinacional. Por um lado, para os depoentes, o teor pedagógico existe porque o consumidor aprende a reconhecer e a defender seus direitos e a exigir do Estado a sua função provedora de recursos para uma justiça mais distributiva. Por outro lado, foi ressaltado que, para o acusado (o agente econômico), a pena tem uma função pedagógica, pois ela expressa uma justiça distributiva e tende a marcar aqueles que têm uma obrigação reparatória, como é exemplificado abaixo por um dos depoimentos: 
O código diz o seguinte: Sr. Fornecedor ou empresário, cumpra os direitos básicos do cidadão que você ganha muito mais e, consequentemente, você vai ter uma clientela fidelizada, o que representa ganho consequente, que é o seu objetivo. (Entrevistado 5 )

F - A cultura política e a relação dos JECDCs com os consumidores segundo os juízes. Ao tratar da democracia, Tocqueville (1977) cuida do princípio da igualdade em contraposição aos privilégios de classe ou profissão e defende a imprescindibilidade da igualdade de condições e de possibilidades para todos, concluindo que não pode existir liberdade na democracia fundamentada na desigualdade. Heller e Fehér (1998) reforçam essa questão, ao afirmar que, diferentemente de liberdade e vida (valores incondicionais), igualdade e justiça devem ser entendidas como valores relacionais, que visam a igualar, isto é, são relativos a algo qualificado (igualdade de direitos, de gênero etc.), resumindo a relação entre eles como: "igual liberdade para todos" e "iguais oportunidades de vida para todos". Logo, a justiça deve se apoiar na combinação de relatividade para os valores da própria justiça e imparcialidade quanto a sentimentos pessoais em favor de um grupo. Tal proposição, contextualizada sob a perspectiva da cultura política brasileira, sofreu, ao longo dos tempos, a influência de julgamentos profundamente parciais, no sentido de particularizantes, em função de questões que desigualam, orientadas por uma relativização dos valores e das normas, tal como consagrado na frase: "Você sabe com quem está falando?" (DA MATTA, 1991). Como a relação da tradição de cultura política impacta na relação dos consumidores com os JECDCs? Todos os entrevistados concordaram que os juizados devem aplicar o direito como promoção da igualdade social, no sentido relacional da justiça mencionado acima, e seis concordaram que os objetivos dos Juizados Especiais, nessa modalidade de legislação, ajudam a desfazer a ideia de que a justiça só beneficia os ricos. Portanto, sua ação impacta na transformação dos valores de cultura política. Quatro deles foram mais taxativos, ao discordarem da assertiva de que os Juizados devam ignorar as questões sociais subjacentes dos envolvidos na condição de consumidores. Ademais, seis entrevistados concordaram que os JECDCs devem contribuir para o empoderamento dos indivíduos no sentido de uma afirmação de 
identidade consumerista e da formação de uma consciência crítica sobre a condição do consumidor em uma economia de mercado. Para a maioria dos juízes, seis, os Juizados Especiais Cíveis de Defesa do Consumidor podem ser associados a um espaço duplamente qualificado para o exercício da cidadania, tanto por aproximar o Judiciário das pessoas mais simples, que, antes da gratuidade e simplicidade, jamais poderiam acessar a complexa e custosa justiça comum, como por exercer um papel verdadeiramente distributivo de direitos e da própria justiça. (BENJAMIN, A. H. V. et al., 2009).

G - A percepção dos juízes sobre valores e cultura política nos próprios JECDCs. Perguntados se os JECDCs contribuem para superar os modelos tradicionais brasileiros de cultura política, os entrevistados se posicionaram como segue. Seis deles comungam a crença sobre a contribuição efetiva do sistema jurídico e da legislação aplicada pelos JECDCs para a superação da tradição de cultura política mais familista e clientelista, baseada na troca de favores. Um considerou que a ação dos juizados, por si só, não é um fator de mudança de valores. Dentre os que acreditam na contribuição dos JECDCs para superar as tradições que desigualam, no sentido analisado por Da Matta, os motivos são: (i) modificou-se a compreensão dos juízes e dos funcionários em relação ao papel do Judiciário como explicitado na Constituição Federal de 1988; (ii) tem havido uma maior qualificação e compromisso dos funcionários públicos vinculados ao Judiciário, posteriormente à Constituição de 1988; (iii) há um aumento da informação para o cidadão; (iv) há uma maior fiscalização por parte de órgãos, como o Ministério Público; (v) há um maior controle da magistratura exercido pelo Conselho Nacional de Justiça; e (vi) há um importante papel desempenhado pela Imprensa. Além desses motivos, um entrevistado conferiu o mérito das mudanças à própria lei consumerista, pois entende que essa lei já tem "um espírito cidadão" que visa à proteção do mais vulnerável, "[...]daquele que, na relação comercial contratualista, é o mais fraco[...]" (Entrevistado 6). Outro juiz conferiu ao sistema dos Juizados Especiais o mérito de dificultar práticas de cultura política baseadas na troca de favores, corrupção ou clientelismo, porque o sistema judiciário agora simplifica e facilita o acesso à justiça por meio da conciliação. A conciliação é mais dialógica (negociação) e 
resolve a disputa de interesses, instigando a função social da reciprocidade para a resolução de conflitos (LANIADO, 2001). Por fim, atuar no sistema dos Juizados Especiais contribui para a própria formação dos valores dos que nele participam, como é ilustrado pela declaração que se segue:

...sobretudo o juiz que labora num Juizado do Consumidor, ele tem que se adequar ao perfil de um juiz mais célere, de um juiz dinâmico, de um juiz que sentencia em audiência ou que marca a data para sentenciar; não é como na justiça comum; fica menos apegado a formalidades, usa uma linguagem mais acessível, tendo em vista que o consumidor muitas vezes vem desacompanhado de advogado; um procedimento mais simples, decisões mais rápidas. ( Entrevistado 4 )

\section{Considerações finais}

A criação dos Juizados Especiais Cíveis para a defesa do consumidor foi uma medida jurídico-constitucional que visou a contribuir para a nova ordem democrática no Brasil, com ênfase na ampliação dos direitos e no acesso à justiça. Os JECDCs permitem uma atitude cidadã mais contestatória, pois formam um espaço para a demanda por mais cidadania. Ampliam a ação do Estado de direito mediante a ação de órgãos promotores de uma justiça mais simples e gratuita, que possa confirmar a participação social por meio da demanda consumerista, forçando o direito do consumidor a assumir o caráter de interesse social e seus efeitos sobre os indivíduos.

Os resultados deste estudo de caso apontam que, mesmo sem os investimentos devidos dos poderes públicos para estruturar rapidamente esse setor da Justiça, há uma adesão maior do cidadão, a despeito das dificuldades reais para ser atendido. Do lado dos poderes públicos, há uma lenta transformação dos valores de cultura política que impregnam o aparelho do Estado e as funções públicas. Do lado da população demandante, ter acesso aos Juizados educa, pois se exercita a atitude de contestar, cobrar, perquirir e buscar direitos, ou seja, ficar atento aos direitos do consumidor fomenta o desenvolvimento de uma cultura da vigilância e participação da cidadania. Não são direitos ou valores de grande magnitude para a 
ordem social democrática, porém interferem nas filigranas das ações cotidianas dos indivíduos, ao despertar o interesse por questionamentos realizados na esfera pública.

Para a população que busca os direitos em tela, os juizados especiais oferecem mais oportunidades de resolver questões relativas à melhoria das condições de vida em uma sociedade que é dominada pelas relações de mercado. Ademais, os JECDCs contribuem para uma menor acomodação do cidadão no "jeitinho brasileiro" de resolver conflitos informalmente, inclusive no âmbito das empresas privadas e públicas, ao fomentarem um relacionamento mais direto entre o negociante e seus clientes.

Finalmente, pode-se dizer que tanto os dados coletados junto aos arquivos do Judiciário como o conteúdo das entrevistas realizadas se movem em um sentido convergente para afirmar que o sistema dos juizados e a (nova) lei induzem uma mudança do comportamento cívico existente. Do ponto de vista da visibilidade e da opinião pública, o desempenho dos Juizados Especiais se encontra, de certa maneira, talvez pela intensa procura, fortalecido pelo prestígio popular por eles alcançado.

Recebido em: 26.2.2009

Aprovado em: 10.3.2010

\section{Referências}

ALMEIDA, J. B. A proteção Jurídica do Consumidor. São Paulo: Saraiva. 2000.

ALMEIDA, T. O. de. A cidadania e os interesses difusos. V Congresso SMMP. Porto. 1998. .: http://www.smmp.pt/online/v_congresso/ teresa_almeida.pdf. Acessado 10/03/2006.

BENJAMIN, A. H. V., MARQUES, C. L., BESSA, L. R.. Manual de Direito do Consumidor. 2a edição. São Paulo:Editora Revista dos Tribunais.2009

BOBBIO, N. A era dos direitos. Rio de Janeiro: Campus. 1992.

CAMPILONGO, C. F. Direito e Democracia. São Paulo: Max Limonad. 1997. 
CAPPELLETTI, M. Acesso à Justiça. Porto Alegre: Sérgio Antônio Fabris. 1998.

CAVALIERI FILHO, S. O direito do consumidor no limiar do século XXI. In: Revista Cidadania e Justiça. 2o semestre de 1999.

COMPARATO, F. K. A afirmação histórica dos Direitos Humanos. São Paulo: Saraiva. 2004.

DANTAS NETO, P. F. "Surf" nas ondas do tempo: do carlismo histórico ao carlismo pós-carlista. Caderno CRH, Salvador, n. 39, p. 213-255, jul./dez. 2003.

DA MATTA, R. A casa e a rua. Rio, Guanabara Koogan. 1991.

DIAGNÓSTICO sobre os Juizados Especiais Cíveis. Ministério da Justiça. 2006. http://www.mj.gov.br/reforma/pdf/publicacoes/ Diagnóstico\%20dos\%20Juizados\%20Especiais.pdf . Consultado em 18/03/2007.

DOMINGUES, J. M. Interpretando a Modernidade: imaginário e instituições. Rio de Janeiro: Editora FGV. 2002.

DURKHEIM, É. As Regras do Método Sociológico. São Paulo: Martin Claret. 2002.

FARIA, J. E. (Org.). Direitos Humanos, Direitos Sociais e Justiça. São Paulo: Malheiros. 2002.

FORTUNY, M. A.. Direitos do Consumidor a emergência de um novo paradigma no direito moderno. In: Os "novos" direitos no Brasil: natureza e perspectivas: uma visão básica das novas conflituosidades jurídicas. Org. WOLKMER, A. C. \& LEITE, J. R. M.. São Paulo: Saraiva. 2003.

FRIEDMAN, L. M. A history of American Law. New York: W. W. Norton \& Company,1984. Disponível em: http://www.stephankinsella.com/ texts/friedman_history.pdf . Acessado em 05/03/2006.

GRINOVER, A. P. Defesa do meio ambiente em juízo como conquista da cidadania. Revista de Processo. São Paulo, v.22, n88, out./dez. 1997, p.142-147

GUIA de responsabilidade social para o consumidor. IDEC. 2004. Disponível em : http://www.idec.org.br/biblioteca.asp. Consultado em $18 / 03 / 2007$. 
HELLER, A. Além da justiça. Rio de Janeiro: Civ. Brasileira. 1998.

HELLER, A. \& FEHÉR, F. A condição pós-moderna. Rio de Janeiro: Civ. Brasileira. 1998.

HOESCHL, H. C. A vida digital e os direitos da sétima dimensão. 22.04.97. http://www.digesto.net/ddigital/digital/Panorama1.htm. Acessado em 10/03/2006.

IDEC. Histórico. Disponível em: http://www.idec.org.br/vitorias_ listar.asp. Consultado em 18/03/2007.

IVO, A. B. L. Metamorfose da questão democrática: governabilidade e pobreza. Buenos Aires: CLACSO.2001.

JUCÁ, F. P. Judicialização da política e politização do judiciário. In: Revista Ciência Jurídica, no 85 - janeiro/fevereiro/1999.

LANIADO, R.N. Desempenho institucional e justiça em relação à exclusão social no Brasil contemporâneo. In: Caderno CRH, no 35 , Jul-Dez/2001.

. Troca e reciprocidade no campo da cultura política. In:

Estado e Sociedade, Vol. XVI - noํ1-2, UNB, Jan-Dez/2001.

LEFORT, C. Pensando o político: ensaios sobre democracia, revolução e liberdade. Rio de Janeiro: Paz e Terra. 1991.

LOPES, S.M. Os Juizados de Defesa do Consumidor em Salvador: a institucionalização dos direitos e a percepção dos juízes em relação à cidadania e justiça social. Dissertação de Mestrado, Programa de Pós-Graduação em Ciências Sociais, Universidade Federal da Bahia, 2007 (103 pgs.).

MANCUSO, R. C. Interesses difusos. Conceito e legitimação para agir. São Paulo: Editora Revista dos Tribunais. 1994.

MARSHALL, T. H. Cidadania, classe social e status. Rio de Janeiro: Zahar, 1967.

MILANI, C. R. S.. Políticas públicas locais e participação na Bahia: o dilema gestão versus política. Sociologias. Porto Alegre, n. 16, 2006.

MILANI, C.R.S. \& LANIADO, R.N. Espaço mundial e ordem política contemporânea: uma agenda de pesquisa para um novo sentido da internacionalização. Caderno CRH (UFBA). Vol 1, noำ8, 2006. 
MIRANDA, A.N.M.; PETRILLO, M.R.A. \& OLIVEIRA FILHO, W.R. Origens históricas dos Juizados Especiais de Pequenas Causas e sua problemática atual. 2004. Disponível em: http://www.estacio.br/site/ juizados especiais/artigofinal grupo1.pdf. Acesso em: 04/03/2006.

NUNES, E. A gramática política do Brasil: clientelismo e insulamento burocrático. Rio de janeiro - Brasília: Jorge Zahar - Enap, 1996.

OLIVEIRA, L.R.C. Entre o justo e o solidário: os dilemas dos direitos de cidadania no Brasil e nos Estados Unidos. In: SOUZA, J. (Org.) 0 malandro e o protestante. Brasília, UNB. 1999.

PEDRON, F.; Barbosa Q.; CAFFARATE \& MACHADO, V. Evolução histórica do Direito do Consumidor. Jus Navigandi, Teresina, ano 4, n. 41, maio 2000. Disponível em: < http://jus2.uol.com.br/doutrina/ texto.asp?id $=687>$. Acesso em: 18 set. 2006.

PIOVESAN, F. Temas de Direitos Humanos. São Paulo: Max Limonad. 2003.

RIBEIRO, S. M. R. Reforma do aparelho de Estado no Brasil: uma comparação entre s propostas dos anos 60 e 90 . VII Congresso Internacional Del CLAD sobre la Reforma Del Estado y de la Administración Pública. Lisboa, Portugal. 8 a 11 Outubro 2002.

WATANABE, K.; SADEK, M.T.; FERRAZ, L.S. \& LIMA, F.D. Juizados Especiais Cíveis - estudo. http://www.cebepej.org.br/pdf/DJEC.pdf. 2006.

SADEK, M.T. Palavras da Professora Maria Tereza Sadek. 2006. Disponível em: http://pyxis.cnj.gov.br/encontro1/Palavra_Professora Maria Tereza Sadek .pdf. Consultado em 18/03/2007.

SANTOS, B.S. Reinventar a democracia: Entre o pré-contratualismo e o pós-contratualismo. In: Os sentidos da democracia. Orgs. OLIVEIRA, F. de, PAOLI, M. C.. Petrópolis: Ed. Vozes, 1999.

SERRANO, P. J. Introdução ao Direito do Consumidor. Barueri-SP: Manole. 2003.

SOUZA, C. A nova gestão pública. Cadernos da Fundação Luis Eduardo Magalhães. $n$ 1. Salvador. 2001. Disponível em: $\underline{w w w . f l e m . ~}$ org.br/cadernos1/cadernosflem1-novagestaopublica.pdf. Acessado em: junho 2007. 
TEIXEIRA, M.R.R. \& LANIADO, R.N. Justiça e desigualdades: o descompasso da cidadania como forma de exclusão social. In: Caderno do CRH, Vol. 17 - № 40, janeiro/abril 2004.

TESHEINER, J. M. Direitos Coletivos - conceito e classificação: estudo de texto de Hermes Zanetti Júnior. Rio Grande do Sul. 2005. Disponível em: http://www.tex.pro.br. Acessado em 18 set. 2006.

TOCQUEVILLE, A. Democracia na América. São Paulo, Ed. Itatiaia/ Edição USP, 1977.

TOURAINE, A.. O que é a democracia. Petrópolis: Vozes. 1996.

VERGARA, S.H.C. Impactos do direito do consumidor nas práticas empresárias. Rio de Janeiro: Ed. FGV. 2003

VON RONDOW, C. S. Proteção constitucional do consumidor. Jus Navigandi, Teresina, ano 6, n. 54, fev. 2002. Disponível em: < http:// jus2.uol.com.br/doutrina/texto.asp?id=2694>. Acessado em: 18 set. 2006.

WEBER, M. A Ética protestante e o espírito do capitalismo. São Paulo: Martin Claret. 2004.

WOLKMER, A.C. \& LEITE, J.R.M. Introdução aos fundamentos de uma teoria dos "novos direitos. In: Os "novos" direitos no Brasil: natureza e perspectivas: uma visão básica das novas conflituosidades jurídicas. São Paulo: Saraiva. 2003.

\section{Abstract \\ Special Consumer Defense Courts: expanding rights within democracy}

The present paper is a case study analyzing the institutionalization of consumers' rights through the implantation of Special Consumer Defense Courts in the city of Salvador, state of Bahia, during the years 2000- 2005. We look at how access to justice, in accordance with the principles and premises of the 1988 Constitution, has actually unfolded. This study in political sociology is situated within the ambit of social justice and the broadening of modern rights that the State has operationalized through some specific organs. Our data reveal that the consumer rights included in the legal services provided through these Special Courts contribute toward raising and broadening people's consciousness on the role of rights within social relations, at the site where consumers and economic forces (firms) 
confront another, within contemporary capitalism. Firstly, resorting to the courts is important in order to validate consumers' grievances and to educate them to better understand the relevance of rights; in the second place, the services provided by these courts show that State action in providing legal services is not always able to provide adequate attention to citizens' demands, given the paucity of resources available for these purposes. However, in general terms we can assert that access to public mechanisms of justice has contributed to broadening citizenship and toward a political culture that emphasizes the role of rights in the plural forms through which today's subject-citizen is constituted.

Keywords: special courts, consumers' rights, citizenship, democracy. 